\title{
The Effect of Intravenously and Intra-arterially Delivered Human Umbilical Cord Blood Mononuclear Cell on Cortical Neurogenesis of Post-Ischemic Stroke Rat Brain
}

\author{
Sastia Winda Astuti ${ }^{1,2}$, Isabella Kurnia Liem ${ }^{3,4,5 *}$, Yetty Ramli ${ }^{4,6}$ \\ ${ }^{1}$ Master Program in Biomedical Sciences, Faculty of Medicine, Universitas Indonesia, Jakarta, Indonesia; ${ }^{2}$ Department of \\ Anatomy, Faculty of Medicine, Gunadarma University, Depok, Indonesia; ${ }^{3}$ Department of Anatomy, Faculty of Medicine, \\ Universitas Indonesia, Jakarta, Indonesia; ${ }^{4}$ Stem Cell Medical Technology Integrated Service Unit, Faculty of Medicine, \\ Universitas Indonesia, Cipto Mangunkusumo Hospital, Jakarta, Indonesia; ${ }^{5}$ Stem Cell and Tissue Engineering Cluster, Indonesia \\ Medical Education and Research Institute, Faculty of Medicine, Universitas Indonesia, Jakarta, Indonesia; ${ }^{6}$ Department of \\ Neurology, Faculty of Medicine, Universitas Indonesia, Cipto Mangunkusumo National Hospital, Jakarta, Indonesia
}

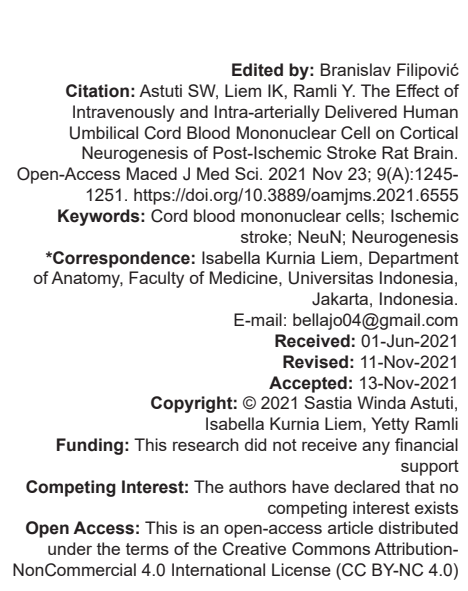

\section{Introduction}

Stroke is that the second leading reason behind death and therefore the third leading explanation for disability worldwide. Globally, $70 \%$ of strokes and $87 \%$ of both stroke-related deaths and disability-adjusted life years occur in low- and middle-income countries. Over the past four decades, stroke incidence in these countries has over doubled [1]. According to the World Stroke Organization, there are over 13.7 million new strokes each year. Globally, one in four people over age 25 will have a stroke in their lifetime [2]. The World Health Organization reported that cerebrovascular diseases (stroke) accounted for 5.5 million deaths worldwide, equivalent to $9.6 \%$ of all deaths [3]. Stroke estimated to affect one for every six people worldwide with a mortality rate as high as one per 20 deaths with most of the death occurred in developing countries, and ischemic stroke was the most common type [4].

Stroke therapy strategies have been developed with two main objectives, namely, restoration of brain flow and minimizing the effects of neuronal damage due to ischemia. Research on stroke therapy over the past 20 years has witnessed significant therapeutic advances in the form of mechanical thrombectomy, antiplatelet agents, carotid endarterectomy, thrombolytics, anticoagulant therapy, neuroprotective agents, and treatment of associated risk factors such as dyslipidemia, hypertension, and diabetes. However, studies regarding the effective administration of neuroprotectants and current therapeutic protocols remain suboptimal. In recent years, several researchers have been working hard to look for neuroprotective agents in the acute stroke phase and for drugs to repair neurons in the chronic stroke phase [5]. However, in 
some developed countries, only a small proportion of stroke patients receive therapy [6] and many stroke patients, even though they have been treated, still leave sequelae [7]. Kumar et al. stated that nearly $50 \%$ of stroke sufferers experience sequelae [8].

In therapy for ischemic stroke we need invasive therapies without clinical sequelae, thus cell-based therapy has emerged as a new approach to reduce neurological deficits and enhance recovery after stroke. The use of umbilical cord blood mononuclear cells (MNCs) is one of the better alternative cell therapies compared to common and frequently used cell therapy such as stem cells derived from bone marrow [9]. MNC cord blood is more promising because it has greater viability, has low immunogenicity, and has a lower risk for the occurrence of disease transmission [10]. Human cord blood mononuclear cells (CB-MNCs) are rich in progenitor cells and contain numerous endothelial cell precursors. This CB-MNC also contains CD34+ which shows an increase in angiogenesis in the penumbral tissue after transplanted CD34+ cells, either systemically or intracerebral [11].

The route of administration has been major concern in cell therapy for neurological disease. The route of administration of cells selected for therapy is the key to migration and the final destination of the transplanted cells. Many studies have been conducted to show the effectiveness of cell-based therapy by differentiating the route (intra-arterial/IA, intravenous/ IV, and intraparenchymal/IP) with the result that intraarterially was more superior and safer compared with the other routes. This hypothesis arises because IA route showed that larger amount of injected cells entered the site of injury compared to the IV route. In the IV route, the cells have higher possibility to enterapt in the lung and in heart, liver, and spleen as they must pass through peripheral organs; consequently, the cell amount will be less in the injury site [12], [13]. Actually, route on intra-arterial administration will also pass through several peripheral organs, but a little more delivery of these cells to the brain. Animal studies have shown that there is greater cell implantation in IA transmission to ischemic tissue compared with IV distributions of similar concentrations [14]. However, IV administration has an advantage because of its wide distribution and easy access to the administration.

Recently, an open-label prospective human study demonstrated safety and feasibility with IV mononuclear cell infusion in 10 patients with acute stroke [15]. No effect of human CB-MNC implantation in decreasing infarct area and safety of xenogenic was confirmed by study through IV and IA for brain ischemia in rats [16]. It is not known which one is more effective, IV or IA implantation, in post-stroke brain tissue repair. Therefore, the effectiveness of MNC administration and biological changes in brain tissue needs to be seen and explored more. Recent study was an experimental research to see neurogenesis in the brain tissue of acute to subacute ischemic stroke rat.

\section{Methods}

This experimental study used an ischemic stroke rat (middle cerebral artery occlusion, $n=24$ ). The animals were divided into four groups with six rats in each group: Normal (control), stroke (MCAO+IA Placebo, $\mathrm{NaCl} 300 \mu \mathrm{l}$ ), stroke with IA CB-MNC administration (MCAO-IA), and stroke with IV CB-MNC administration (MCAO-IV). The Wistar rats (male, 10 weeks, 200-250 g) were provided from National Institute of Health Research and Development. The rats were housed in a constant temperature, under a $12 \mathrm{~h}$ dark/light cycle and supplied with laboratory chow and water ad libitum. The research has been approved by the Research Ethics Committee of Faculty of Medicine Universitas Indonesia No. 548/UN2.F1/ETIK/V/2017.

\section{Ischemic stroke induction}

The induction followed the Koizumi's method, that is, middle cerebral artery occlusion (MCAO). The rats were anesthetized with ketamine and xylazine in 1:1 ratio. The common carotid artery was permanently tied using 3.0 nylon thread and threaded $\pm 5 \mathrm{~cm}$ through the left side internal carotid artery. After being tied, the rat's neck skin was sewn back.

\section{Cell transplant}

One week after the induction, the treatment groups or rats were injected with 300,000 cells/rat $\left(1 \times 10^{6} / \mathrm{kg}\right.$ body weight) in $300 \mu \mathrm{l} \mathrm{NaCl}$ of CD34+human CB-MNC (the cells from the isolation of umbilical cord blood samples from donor cryopreservation by PT. Cellsafe International and Stem cell medical technology integrated research unit Cipto Mangunkusumo Hospital, Jakarta) intravenously (through vein of the tail) and intraarterially (through contralateral common carotid artery). The MCAO group received $300 \mu \mathrm{l} \mathrm{NaCl}$ intra-arterially.

\section{Brain tissue collection}

All groups were decapitated at the $14^{\text {th }}$ day. Before being sacrificed, rats were anesthetized using intraperitoneal injection of ketamine $(25 \mathrm{mg} / \mathrm{kg})$ and xylazine $(15 \mathrm{mg} / \mathrm{kg}$ ). A small craniectomy was performed over the right fissure with intermediate cerebral artery branching. After that, the brain was collected, cut $4 \mathrm{~mm}$ in front of the bregma area (to view the cortical area; Figure 1) and fixed in formalin solution for $24 \mathrm{~h}$. The organs were then embedded in paraffin and cut into $5 \mu \mathrm{m}$ thick. 


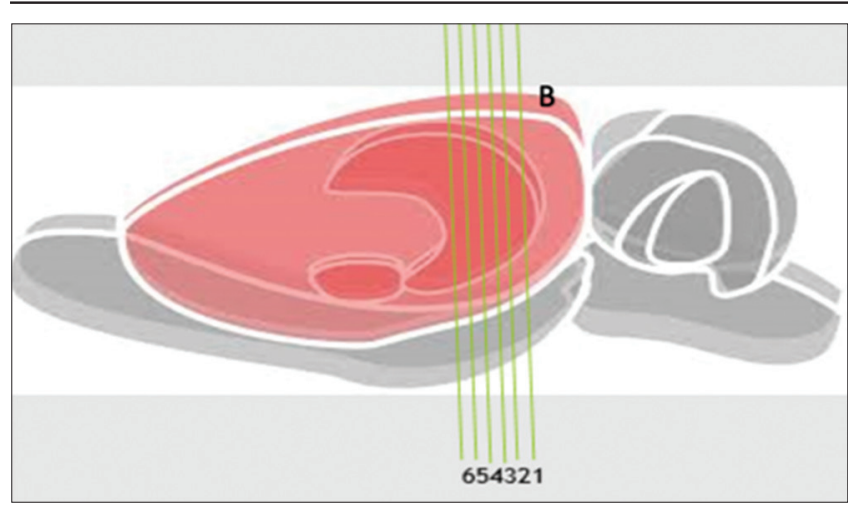

Figure 1: Illustration of the brain serial section. Pieces number 1, 3, and 5 for hematoxylin-eosin staining, pieces number 2, 4, and 6 for anti-NeuN antibody immunostaining. B: Bregma

\section{Hematoxylin-eosin (HE) staining}

As a routine dyeing method, the tissue was heated on a slide warmer at $56^{\circ} \mathrm{C}$ for $30-45 \mathrm{~min}$. The tissues were deparaffinized 3 times in xylol solution for 5 min, rehydrated using serial decreased of alcohol concentrations (absolute ethanol, ethanol 96\%, ethanol $80 \%$, and ethanol $70 \% ; 5$ min each), and stained with hematoxylin and eosin. After staining, the tissue was dehydrated with serial increased alcohol concentration (ethanol $70 \%$, ethanol $80 \%$, ethanol $90 \%$, and absolute ethanol; $5 \mathrm{~min}$ each), cleared by immersing them 3 times in xylol solution for $5 \mathrm{~min}$. At the end, the tissue was mounted with entellan and covered by cover glass.

\section{Immunostaining}

Anti-NeuN antibody (1:500, ab 177487, rabbit, Abcam) was used to stain the nuclei of the neuron. The tissue was deparaffinized using xylol for $30 \mathrm{~min}$ and rehydrated using serial decrease of alcohol concentration. The tissues were blocked with $3 \%$ $\mathrm{H}_{2} \mathrm{O}_{2}$ /methanol and incubated in $95^{\circ} \mathrm{C}$ of Tris EDTA for $45 \mathrm{~min}$. After that, they were cooled and washed with Tween 20 in PBS. The staining was performed with a 1:500 diluted with crystal clear dilution, incubated overnight at $4^{\circ} \mathrm{C}$, and washed with Tween 20 in PBS. Histofine Nichirei was given as secondary antibody for $30 \mathrm{~min}$, followed by incubation in DAB chromogen for 1 min, counterstained with hematoxylin, and bluing with lithium carbonate.

\section{Observation and data analysis}

Histological observation was done using Nikon Corporation microscope, Nikon Eclipse TE-2000U, Tokyo, Japan. At $\times 20$ objective lens, HE imaging can see general picture of gliosis and shrunken cells. At a magnification of the objective lens $\times 40$ for each large field of view, the ratio of dead cells to the total number of cells consisting of healthy cells and shrunken cells is calculated and calculates the area of gliosis using the image raster application. Observations were made in five broad and consistent perspectives in each sample group when we calculate the mean value (in one sample group, there were three stocks). All parameters were tested one-way ANOVA because they were normal and homogeneous data. After each using ANOVA, if $p<0.05$, the post hoc LSD test was performed to determine which group was significantly different.

\section{Results}

In HE staining, glial cells, astrocytes, and neurons were not easy to differentiate; however, we could see the morphological differences of the cells between groups (Figure 2a, b, d, e, g, h, j, k). Control group (healthy group), there was difference between the nucleus and cytoplasm of neuron cells. In the MCAO group, the nucleus and cytoplasm were not easy to differentiate; the cells were high density and depreciated. In MCAO group, the cells had diffuse eosinophilia, which were beginning to cytoplasmic shrink and intense eosinophilia accompanied by shrinkage. In MCAO group, brain tissue necrosis was represented by necrotic condensed (pyknotic) nuclei of glial cells.

There was a cells mass formation known as gliosis. In the treatment groups, dead cells and gliosis were still visible, but there was an improvement in cell morphology. Number of dead cells and gliosis area were significantly decreased in the treatment groups compared to the MCAO group (Figures 2 and 3a-c).

With the specific neuron immunohistochemistry staining (Figure 2c, f, i, I), brown neurons appear to be mature and appear to be a meaningful comparison of the number of neurons in the stroke group and the normal group and IV and IA therapy. For neurons that are not yet mature, they will not be colored. Therapy groups IV and IA showed that there was no significant difference in the number of mature neurons. Comparison in the number of neurons (Figure $3 \mathrm{c}$ ), there appears more in the number of mature neurons in the IA (MCAO-IA = 52) therapy group when compared to IV (MCAO-IV = 50).

\section{Discussion}

Our result showed that there was a significant decrease of cells death ratio between MCAO group and therapy group (MCAO-IA and MCAO-IV), which implied that CB-MNC could prevent the progressivity of cortical cells death. The presence of cell and tissue hypoxia leads to several mechanisms, the excitotoxicity of neurotransmitters (glutamate and aspartate), ion imbalances, and oxidative stress. These three 


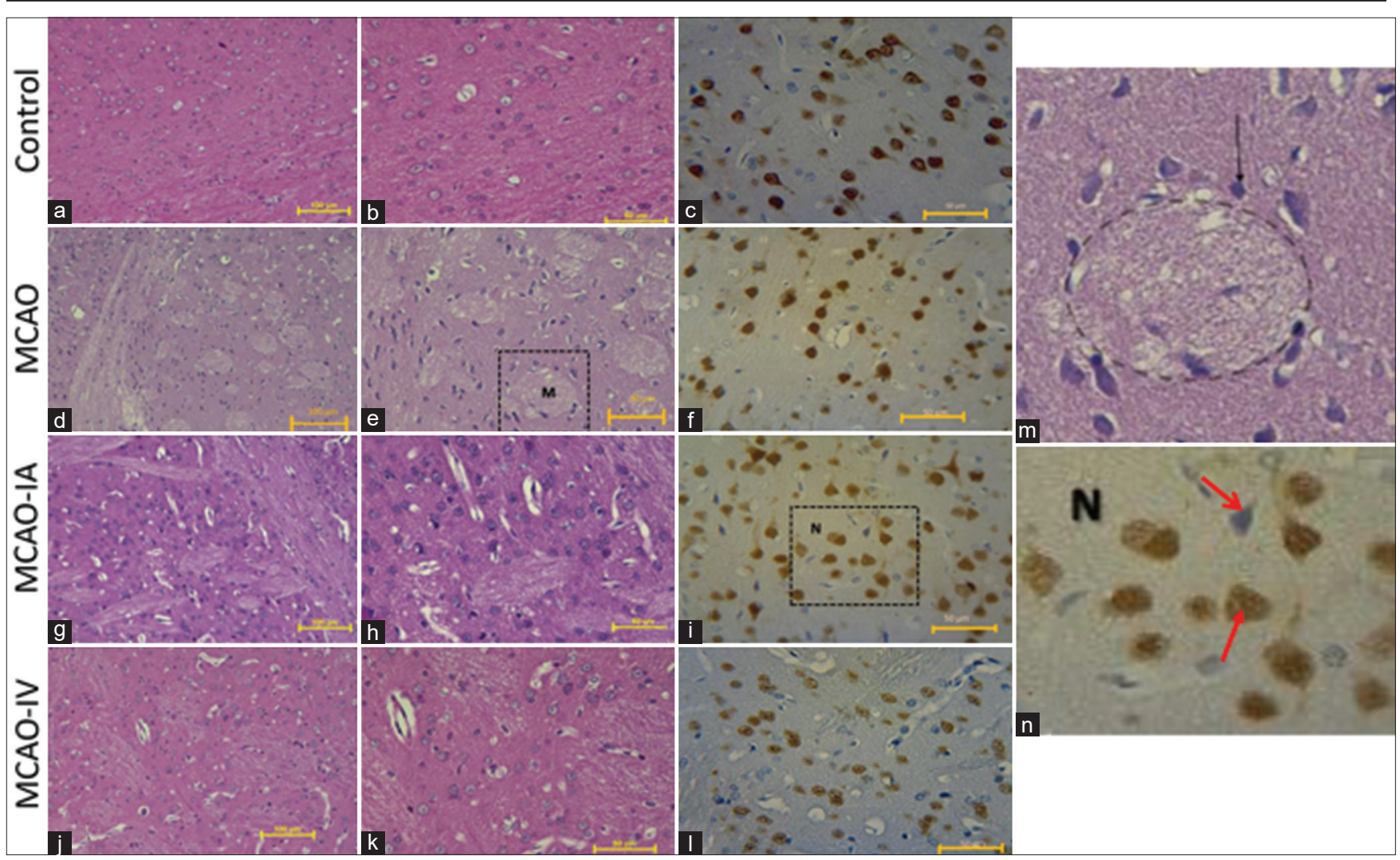

Figure 2: Photomicrograph of cortex area of the brain stained with hematoxylin-eosin and anti-NeuN antibody. (a) HE imaging at $\times 200$ and (b) $\times 400$. (c) Anti-NeuN antibody stain $\times 400$. (a-c) Control group, this image showed figure of a cell that can still be distinguished between the nucleus and the cytoplasm and the IHC showed figure of a mature neuron. (d) HE imaging MCAO group with $\times 200$ and (e) $\times 400$. This image showed a circular area of gliosis and the dead cell with pyknotic stage. For a clearer picture, the areas of gliosis (dash circle) and dead cells (black arrow) are shown in figure $(m)$. ( $f$ ) The IHC description of the MCAO group. This figure showed that the number of mature neurons is less when compared to the control group. For a clearer picture, the mature neuron is shown in figure (n). Figure (n) showed that the mature neurons were brown and glial cell or immature neuron was blue. ( $g$ and $j$ ) The MCAO HE imaging group with IA and IV therapy with $\times 200$ and $(h)$ and $(k) \times 400$. This figure showed that there is still an area of gliosis, but the area was begun to decrease and the number of dead cells is reduced when compared to the MCAO group. The control group as positive control using the cerebellum of rat thus displaying NeuN immunopositive throughout the brain. (i and I) More mature neuron cells compared to the number of neurons in the MCAO group

mechanisms will cause the cell to become necrosis and apoptosis. Cells showed that necrosis was characterized by the presence of nuclear pyknosis and shrunken cells. This research has been proved by Saha et al., 2019, the administration intravenous CB-MNCs are present near brain lessons for treatment acute stroke [17].

This study was found that there were tissue changes in the form of gliosis in the MCAO group which was very significant compared to the control group and therapy group. This happened because gliosis is caused by excessive activation by glial cells. Research conducted by Rafael et al., 2016, the proliferation of glial cells is influenced by several factors including survivin. Astrocytes release several molecules including proinflammatory cytokines TNF- $\alpha$, metalloproteinase, and ROS. Astrocytic cells may contribute to neuroblast migration with the release of stroma-derived factor- $1 \alpha$ (SDF-1) and monocyte chemoattractant protein 1 [18]. Boltze et al. suggested that MNCs provide the most prominent neuroprotective effect, with CD34+ cells seeming to be particularly involved in the protective action of MNCs. MNCs promote neuroprotection at least partly by mechanisms not requiring direct contact to injured neural cells [19]. This study is supported by Laterza et al., 2018, that stroke ischemia causes an inflammatory reaction involving several cellular components that interact to form scar tissue around the edge of the ischemia consisting of astrocytes, microglia, macrophages, and several other components [20].

The presence of gliosis is one of the hypoxic effects of brain tissue due to ischemic stroke. In the MCAO-IA and MCAO-IV groups, there was a reduction in the ratio of dead cells, a reduction in gliosis area and a significant increase in the number of neurons when compared to the MCAO group. This is because some of the cellular components of CB-MNCs assist neurogenesis in the outer cortex after injury suggesting a potential role for CB-MNCs. Our research is strengthened by Lin et al., 2014 [21], which states that giving therapy in the form of neural stem cells has improved neurogenesis in the brain of MCAO rats and proved by Galieva et al. [22]. The research showed the positive effect of CB-MNC transplantation on the migration potential of the stem cells and the integrity of peripheral myelin.

The intravenous and intra-arterial treatment groups showed the difference the number of neurons 


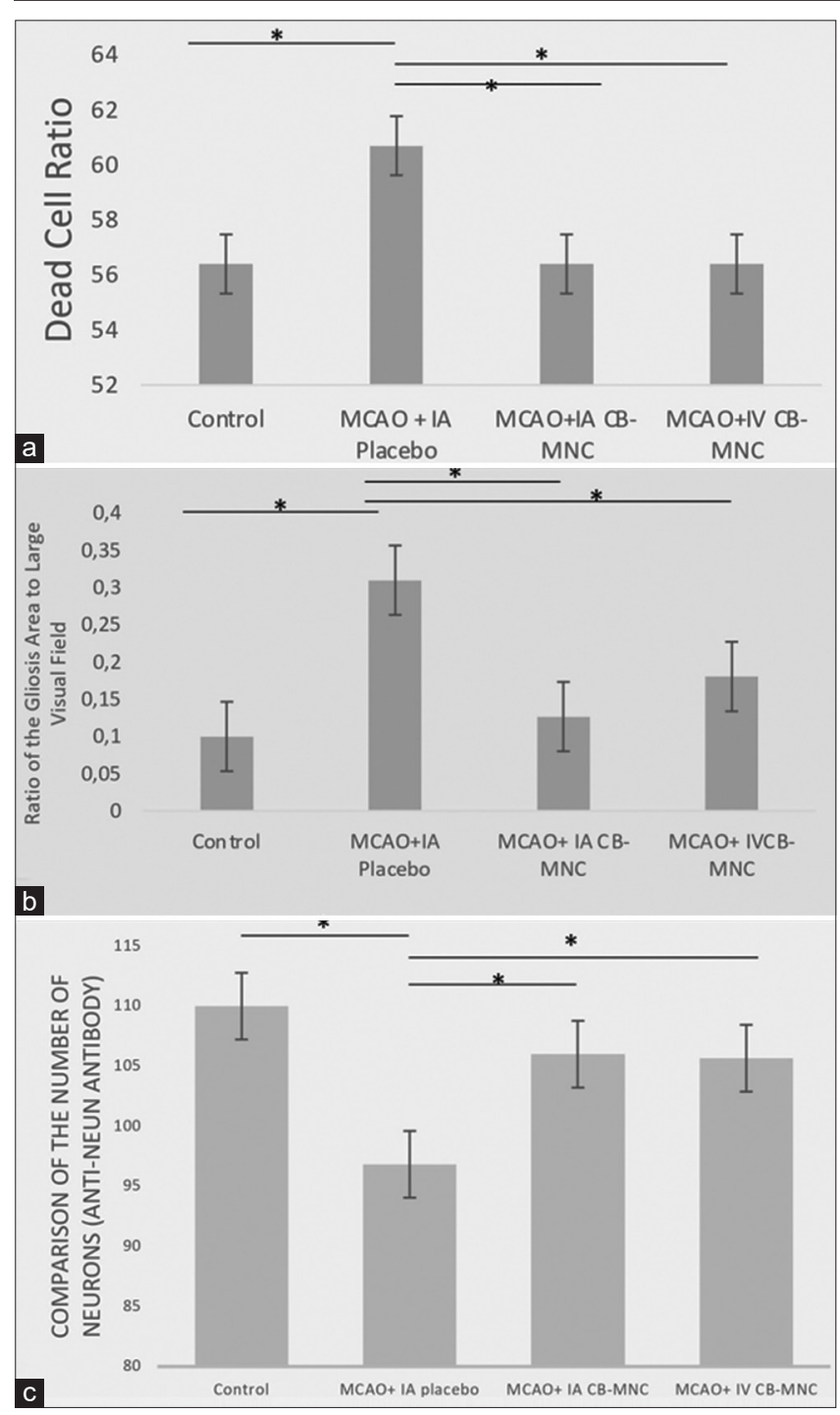

Figure 3: Diagram result of observation. (a) The ratio of dead cells to the number of cells. About $17 \%$ for control, $89 \%$ for MCAO+IA Plaacebo, $34 \%$ for MCAO-IA, 32\% for MCAO-IV. There is a significant difference between the control group with the stroke group and the stroke group with the therapy group $(p<0.05)$. (b) The ratio of the gliosis area to the large visual field. The picture shows in MCAO group showed the largest gliosis area (31\%) and had a significant difference $(p<0.05)$. (c) In the figure with neuron-specific marker, the anti-NeuN antibody showed that in the MCAO group had a decrease in the number of mature neurons (29) and there were significant differences in the control group (50) and the therapy groups (MCAO-IA $=52$; $M C A O-I V=50)(p<0.05)$

(MCAO-IA = 52; MCAO-IV = 50). This occurred in the possibility of a paracrine or autocrine effect. Brain repair after stroke involves a number of different interconnected processes. The most common aspects of brain repair that many types of cell therapies have consistently been shown to enhance are the endogenous formation of new neurons (neurogenesis) in the areas around the infarct [15]. This study was supported by previous research by Ramli et al., CD34 + MNC cord blood given not in large quantities because to see the pluripotent effect of these mononuclear cells demonstrated to exclude angiogenesis and neurogenesis factors including vascular endothelial growth factor (VEGF), nerve growth factor (NGF), and
IGF-1, thrombopoetin17, IL-11, and cytokines that are important for the resistance and differentiation of neural progenitor cells with the potential for neurogenesis [16]. This explanation allows for the improvement of neuronal cells in stroke ischemic animals treated with human umbilical CB-MNC, although it does not see the differentiation of transplanted cells [23].

The subgranular zone of hippocampus dentate gyrus and the subventricular zone of the lateral ventricle are primary sources of neurogenesis in adult mammals. In stroke, there will be a signal in the neurogenic niche by modulation of neural precursor cells proliferation, differentiation, migration, and neuron resistance. Postischemic neurogenesis is seen in the hippocampal CA1 and cortical area [24]. This statement is consistent with our study of the significant increase in the number of neurons between the stroke group and treatment groups $(\mathrm{MCAO}=29$; MCAO-IA = 52; MCAO-IV = 50) $(p<0.05)$. However, this study has not been able to prove the effect of CB-MNC as therapeutic cells.

A study conducted by Taguchi et al. [25] showed that cortical function and neoangiogenesis were better after treatment with CD34+ cells. CB-MNCs mechanisms in stroke may exert a neuroprotective effect. This is proven by in vitro studies, it can protect against glutamate-induced apoptosis by activating the Akt signaling pathway and protects from free radicals. There are several transcription factors expressed by CB-MNCs such as brain-derived neurotropic factor (BDNF), glial cell line-derived neurotrophic factor, NGF, neurotrophin (NT-3), and NT-5 in greater amounts than MNC of peripheral blood. VEGF, BDNF, NT-4, NT-5, and some cytokines and chemokines were suspected to be detected in MNC cord blood supernatant cultures [25]. A study conducted by Rodrigues et al. regarding CB-MNCs transplantation on spinal trauma showed that MNC could improve its function by secreting thrombopoietin and IL-11, a cytokine that is important for neuronal progenitor cell resistance, although there is no differentiation in transplant cells [24]. This is reinforced by Park et al. research that stem cell transplantation led to functional enhancement without differentiation into neurons or astrocytes, which results equally in this study that decreased the gliosis area and increased the number of neurons.

It is known that at the time of stroke, the brain cells are unable to regenerate; however, several studies have shown that neurons and astrocytes can regenerate from isolated cells from the mammalian central nervous system and regeneration is indicated in the hippocampus and SVZ areas of the adult human brain. The presence of neurogenesis in penumbra ischemia of stroke patients is localized in the area around the blood vessels. However, the neuron replacement capacity of the adult central nervous system is very low, with an estimated $10 \%$ of the number of missing neurons. Several factors can increase neurogenesis by stimulating or increasing the resistance of new neurons such as erythropoietin, BDNF, EGF, VEGF, 
and several other growth factors that can help stroke healing [26], [27]. VEGF can increase the regeneration of new neurons in two areas of neuron formation: Gyrus dentate hippocampus and SVZ. VEGF also plays an important role in the plasticity of neurons. VEGF also plays an important role in the plasticity of neurons, while BDNF has a role to reduce the death of neurons with activation of extracellular signal pathways associated with protein kinase. Moreover, BDNF also affects neurogenesis by increasing the regenerative endogenous neurons in the brain and increasing the plasticity of neurons in stroke [26].

Savitz shows that intravenous administration of certain doses has a reduced amount when entering brain tissue because capillaries in the brain are smaller and many are trapped in lung tissue [15]. Therefore, the authors wish to prove that the intra-arterial administration of mononuclear cells is an alternative route. We expect with a dose of $1 \times 10^{6}$ to be injected through the internal carotid artery collaterally which is expected with the same dose into the brain tissue that has infarction. To this end, intravenous and intra-arterial CB-MNCs therapy provides a neurological improvement in the cortical tissue of the brain of experimental animals.

\section{Conclusion}

From this research, it is evident that CB-MNC administration can be an alternative for stroke ischemic therapy because it is proven to increase neurogenesis and reduce gliosis areas. However, there was no difference in neurogenesis in the brain tissue of mice injected with CB-MNC intravenously or intra-arterially.

The limitation in my research is that it does not compare ischemic stroke on day 14 or after (chronic period) so that intravenous and intra-arterial administration charts have the same effect, even though intra-arterial administration has a better effect when compared to intravenous administration.

\section{Acknowledgment}

The authors would like to thank the National Institute of Health Research and Development (Litbangkes), Indonesia; Department of Histology, Faculty of Medicine, Universitas Indonesia, for histological preparation; Cellsafe for preparing the cells; Department of Pathology Anatomy, Faculty of Medicine, Universitas Indonesia, for assistance in histological analysis; Integrated Care Unit for Stem Cell Therapy, National Hospital Cipto Mangunkusumo, for preparing the cells; and Firda Asma'ul Husna for facilitating the manuscript preparation.

\section{References}

1. Johnson W, Onuma O, Owolabi M, Sachdev S. Stroke: A global response is needed. Bull World Health Organ. 2016;94(9):634. https://doi.org/10.2471/blt.16.181636

2. Feigin VL, Nguyen G, Cercy K, Johnson CO, Alam T, Parmar PG, et al. Global, Regional, and Country-Spesific Lifetime Risks of Stoke, 1990 and 2016. N Engl J Med. 2018;379(25):2429-37. PMid:30575491

3. Truelsen T, Begg S, Mathers C. The Global Burden of Cerebrovascular Disease. Geneva: World Health Organization; 2000.

4. Tini K, Dewa I, Samatra PG, Wiryadana KA, Supadmanaba IG Clinical profile of patients with cerebrovascular disease at Stroke Unit, Sanglah General Hospital, Denpasar, Bali. Bali Med J (Bali Med J) 2020;9:129-36. https://doi.org/10.15562/bmj.v9i1.1665

5. Font MA, Arboix A, Krupinski J. Angiogenesis, neurogenesis and neuroplasticity in ischemic stroke. Curr Cardiol Rev. 2010;6:238-44. https://doi.org/10.2174/157340310791658802

6. Friedrich AG, Martins MP, Arau MD, Klamt C, Vedolin L, Garicochea B, et al. Intra-arterial infusion of autologous bone marrow mononuclear cells in patients with moderate to severe middle cerebral artery acute ischemic stroke. Cell Transplant. 2012;21(Suppl 1):13-22. https://doi.org/10.3727/096368912×612512 PMid:22507676

7. Riyadina W, Rahajeng E. Determinan penyakit stroke. J Kesehatan Masyarakat Nasional. 2012;7(7):324-30.

8. Kumar A, Prasad M, Jali VP, Pandit AK, Misra S, Kumar P, et al Bone marrow mononuclear cell therapy in ischaemic stroke: A systematic review. Acta Neurol Scand. 2017;135(5):496-506. https://doi.org/10.1111/ane.12666

PMid:27558274

9. Yang B, Xi X, Aronowski J, Savitz SI. Ischemic stroke may activate bone marrow mononuclear cells to enhance recovery after stroke. Stem Cells Dev. 2012;21(18):3332-40. https://doi.org/10.1089/scd.2012.0037

PMid:22731389

10. Vendrame M, Cassady J, Newcomb J, Butler T, Pennypacker KR, Zigova T, et al. Infusion of human umbilical cord blood cells in a rat model of stroke dose-dependently rescues behavioral deficits and reduces infarct volume. Stroke. 2004;35(10):2390-5. https://doi.org/10.1161/01.str.0000141681.06735.9b

11. Bhasin A, Srivastava MV, Mohanty S, Bhatia R, Kumaran SS Stem cell therapy: A clinical trial of stroke. Clin Neurol Neurosurg. 2013;115(7):1003-8. https://doi.org/10.1016/j. clineuro.2012.10.015 PMid:23183251

12. Guzman R, Choi R, Gera A, De Los Angeles A, Andres RH, Steinberg GK. Intravascular cell replacement therapy for stroke. Neurosurg Focus. 2008;24(3-4):3e4. https://doi.org/10.3171/ foc/2008/24/3-4/e14 PMid: 18341412

13. Chen J, Sanberg PR, Li Y, Wang L, Lu M, Willing AE, et al Intravenous administration of human umbilical cord blood reduces behavioral deficits after stroke in rats. Stroke. 2001;32(11):2682-9. https://doi.org/10.1161/hs1101.098367 PMid:11692034

14. Misra V, Ritchie MM, Stone LL, Low WC, Janardhan V. Stem cell therapy in ischemic stroke: Role of IV and intra-arterial therapy. Neurology. 2012;79(13 Suppl 1):S207-12. https://doi. org/10.1212/wnl.0b013e31826959d2

PMid:23008400

15. Savitz SI. Developing cellular therapies for stroke. Stroke. 


\section{5;46(7):2026-31 PMid:26045599}

16. Ramli Y, Alwahdy AS, Kurniawan M, Juliandi B, Wuyung PE, Susanto YD. Intravenous versus intraarterial transplantation of human umbilical cord blood mononuclear cells for brain ischemia in rats. HAYATI J Biosci. 2017;24(4):187-94. https://doi.org/10.1016/j.hjb.2017.11.002

17. Saha A, Petel S, Li X, Scotland P, Schwartzman J, Filiano AJ, et al. Human umbilical cord blood monocytes, but not adult blood monocytes, rescue brain cells from hypoxic-ichemic injury: mechanistic and therapeutic implicaton. PLoS One. 2019;14(9):e0218906. https://doi.org/10.1371/journal.pone.0218906 PMid:31483780

18. Lima RR, Santana LN, Fernandes RM, Nascimento EM, Oliveira AC, Fernandes LM, et al. Neurodegeneration and glial response after acute striatal stroke: Histological basis for neuroprotective studies. Oxid Med Cell Longev. 2016;2016:3173564. https://doi.org/10.1155/2016/3173564 PMid:28090244

19. Boltze J, Reich DM, Hau S, Reymann KG, Strassburger M, Lobsien $\mathrm{D}$, et al. Assessment of neuroprotective effects of human umbilical cord blood mononuclear cell subpopulations in vitro and in vivo. Cell Transplant. 2012;21(4):723-37. https:// doi.org/10.3727/096368911x586783

PMid:21929866

20. Laterza C, Uoshima T, Wilhelmsson U, Stokowska A, Ge R, Pekny M, et al. 2018 Attenuation of reactive gliosis in stroke-injured mouse brain does not affect neurogenesis from grafted human iPSC-derived neural progenitor. PLoS One. 2018;13(2):e0192118. https://doi.org/10.1371/journal. pone.0192118

PMid:29401502

21. Lin R, Cai J, Nathan C, Wei X, Schleidt S, Rosenwasser R, et al. Neurogenesis is enhanced by stroke in multiple new stem cell niches along the ventricular system at sites of high BBB permeability. Neurobiol Dis. 2014;74:229-39. https://doi.org/10.1016/j.nbd.2014.11.016

PMid:25484283

22. Galieva LR, Mukhamedshina YO, Akhmetzyanova ER, Gilazieva ZE, Arkhipova SS, et al. Influence of genetically modified human umbilical cord blood mononuclear cells on the expression of Schwann cell molecular determinants in spinal cord injury. Hindawi Stem Cells International. 2018;2018:4695275. https://doi.org/10.1155/2018/4695275

23. Rodrigues LP, Iglesias D, Nicola FC, Steffens D, Valentim L, Witczak $A$, et al. Transplantation of mononuclear cells from human umbilical cord blood promotes functional recovery after traumatic spinal cord injury in Wistar rats. Braz $\mathrm{J}$ Med Biol Res. 2012;45(1):49-57. https://doi.org/10.1590/ s0100-879x2011007500162

PMid:22183246

24. Crowley MG, Tajiri N. Exogenous stem cells pioneer a biobridge to the advantage of host brain cells following stroke: New insights for clinical applications. Brain Circ. 2017;3(3):130-4. https://doi.org/10.4103/bc.bc_17_17 PMid:30276314

25. Taguchi A, Soma T, Tanaka $H$, Kanda T, Nishimura $H$, Yoshikawa $\mathrm{H}$, et al. Administration of $\mathrm{CD} 34+$ cells after stroke enhances neurogenesis via angiogenesis in a mouse model. J Clin Investig. 2004;114(3):330-8. https://doi.org/10.1172/ jci200420622

PMid:15286799

26. Pimentel-Coelho PM, Rosado-de-Castro PH, Barbosa LM, Mendez-Otero R. Umbilical cord blood mononuclear cell transplantation for neonatal hypoxic-ischemic encephalopathy. Pediatr Res. 2012;71(4):464-73. https://doi.org/10.1038/ pr.2011.59

PMid:22430382

27. Balami JS, Fricker RA, Chen R. Stem cell therapy for ischaemic stroke: Translation from preclinical studies to clinical treatment. CNS Neurol Disord Drug Targets. 2013;12(2):20919. https://doi.org/10.2174/1871527311312020007 PMid:23394533 